\title{
Metode Pembelajaran Numbered Head Together secara Online terhadap Hasil Belajar IPA Siswa Kelas IV
}

\author{
Puspitasari Tri Anggrainy ${ }^{1 *}$, Mubarak Ahmad2 \\ 1,2 Prodi Pendidikan Guru Sekolah Dasar, Universitas Muhammadiyah Prof. Dr. HAMKA, Jakarta Timur, Indonesia
}

\section{ART ICLE INFO}

Article history:

Received May 09, 2021

Revised May 15, 2021

Accepted July 17, 2021

Available online August 25, 2021

Kata Kunci:

NHT, Pembelajaran IPA

Keywords:

NHT, Science Learning

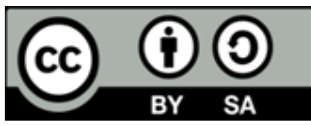

This is an open access article under the CC BY-SA license.

Copyright $(2021$ by Author. Published by Universitas Pendidikan Ganesha.

\begin{abstract}
A B S T R A K
Pelaksanaan pembelajaran pembelajaran jarak jauh ataupun online berlangsung menimbulkan berbagai kendala, di antaranya koneksi internet yang kurang menunjang, rendahnya hasil belajar, dan kesulitan dalam belajar IPA juga disebabkan oleh metode penyampaian guru dalam mengelola pembelajaran yang kurang efektif. Penelitian ini bertujuan menganalisis pengaruh metode pembelajaran Numbered Head Together secara online terhadap hasil belajar IPA siswa kelas IV. Penelitian ini menggunakan jenis penelitian kuantitatif, metode Quasi Experiment dengan Non-Equivalent Control Group Design. Pengambilan sampel menggunakan purposive sampling dengan sampel sebanyak 62 siswa. Subjek penelitian ini terdiri dari dua kelas yaitu kelas kontrol berjumlah 31 siswa dan kelas eksperimen berjumlah 31 siswa. Metode pengumpulan data memakai pre-test serta post-test dengan instrumen penelitian 25 soal pilihan ganda. Metode analisis data memakai uji normalitas Kolmogorov-Smirnov dan uji homogenitas Levene test serta uji hipotesis memakai uji independent sample t-test. Hasil penelitian menunjukkan thitung $=7,419>$ tabel $=2,000$, sehingga tolak $\mathrm{H}_{0}$ terima $\mathrm{H}_{1}$. Maka, ada pengaruh yang signifikan metode pembelajaran Numbered Head Together secara online memberikan pengaruh terhadap hasil belajar IPA siswa kelas IV.
\end{abstract}

\section{A BS TRACT}

This research aims to determine whether there is a significant effect on the science learning outcomes of fourth-grade students who use the Numbered Head Together learning method online. This research was motivated by the COVID-19 pandemic that hit the world, especially Indonesia, one of which required learning activities to be carried out at home or online. During online learning the teacher only uses the lecture and question and answer method, for that we need action to increase student learning outcomes by implementing the Numbered Head Together learning method online. This research uses quantitative research, Quasi Experiment method with Non-Equivalent Control Group Design. Sampling used purposive sampling with a sample of 62 students. The subjects of this study consisted of two classes, namely the control class with 31 students and the experimental class with 31 students. The data collection method used a pre-test and post-test with 25 multiple choice questions as research instruments. The data analysis method used the Kolmogorov-Smirnov normality test and the Levene homogeneity test and the hypothesis test used the independent sample t-test. The research results are convincing if tcount $=7,419>$ ttable $=2,000$, so reject $\mathrm{HO}$ and accept $\mathrm{H1}$. This research concludes that there is a significant effect of the Numbered Head Together online learning method on the fourth-grade students' science learning outcomes.

\section{PENDAHULUAN}

Pendidikan mewujudkan suatu usaha yang dilakukan secara terkendali untuk menciptakan situasi kegiatan belajar mengajar agar peserta didik dapat berpartisipasi aktif dan mampu meningkatkan keahlian dirinya untuk memiliki kualitas spiritual, self-control, kapabilitas, akhlak mulia, serta memiliki keahlian yang diperlukan dirinya, dan lingkungan sekitar (Cahyani \& Suyadi, 2019; Syafril, 2017). Walaupun demikian, akhir-akhir ini dunia dilanda pandemi COVID-19. Pandemi tersebut pula meliputi Indonesia. Pandemi ini menimbulkan dampak pada semua sektor tak terkecuali sektor pendidikan. Menyikapi perihal itu, Kemendikbud melalui Surat Edaran No. 4 Tahun 2020 (Dewi, 2020; Susilawati \& Supriyatno, 2020) menginstruksikan pembelajaran secara online. Pembelajaran secara online ataupun 
daring yang dilakukan disesuaikan dengan keahlian tiap-tiap sekolah. Sejak pandemi COVID-19 yang melanda seluruh dunia, seluruh aktivitas dilakukan secara online ataupun daring termasuk pembelajaran di Indonesia. Perihal ini menimbulkan ketidakefektifan aktivitas belajar mengajar melalui model tersebut karena sistem pembelajaran dilakukan tidak secara langsung antara guru serta peserta didik (Hermanda et al., n.d.; Rahma \& Pujiastuti, 2021).

Namun kenyataannya, pelaksanaan pembelajaran pembelajaran jarak jauh ataupun online berlangsung menimbulkan berbagai kendala, di antaranya koneksi internet yang kurang menunjang (Muhammad Fikri, Muhammad Zaki Ananda, 2021; Rigianti, 2020). Ketidakpahaman orang tua/wali murid memakai gadget, kesulitan guru dalam menerangkan materi pembelajaran secara online, serta lain sebagainya. Kurangnya partisipasi siswa dalam proses belajar mengajar disebabkan guru cenderung menggunakan metode pembelajaran yang masih bersifat konvensional, sehingga siswa tidak mendapat kesempatan untuk berpikir maupun mengungkapkan pendapat baik secara individu ataupun kelompok (Mansyur, 2020; Yulianingsih et al., 2020). Rendahnya hasil belajar dan kesulitan dalam belajar IPA juga disebabkan oleh metode penyampaian guru dalam mengelola pembelajaran yang kurang efektif (Andriyani \& Suniasih, 2021; Puspitorini et al., 2014). Pembelajaran di sekolah belum bisa membuat siswa menjadi aktif di dalam kelas. Padahal keaktifan siswa dalam belajar merupakan kunci keberhasilannya dalam belajar. Oleh karena itu, diperlukan suatu tindakan agar bisa menaikkan nilai siswa dengan materi Kekayaan Sumber Energi di Indonesia siswa/i kelas IV SDN Cilangkap 01 Pagi Jakarta Timur.

Salah satu upaya yang bisa dilaksanakan yaitu dengan mengimplementasikan metode pembelajaran Numbered Head Together (NHT) secara online. Hal ini diharapkan bisa mengoptimalkan kembali hasil belajar IPA. Numbered Head Together (NHT) memakai sistem penomoran tipe model pembelajaran kooperatif ataupun secara kerja sama yang didesain untuk memengaruhi pola hubungan siswa di dalam kelas (Susilo \& Khabibah, 2010; SY et al., 2016). Metode pembelajaran ini dapat menstimulasi siswa untuk meningkatkan kooperatif siswa. Metode ini bisa digunakan buat seluruh muatan pelajaran serta seluruh tingkatan usia peserta didik (Arjuniwati, 2019; putra, 2019). Salah satunya diterapkan dalam pembelajaran IPA. Ilmu pengetahuan alam adalah suatu rencana yang memiliki keterkaitan dengan konsep yang ada sebelumnya sebagai hasil dari suatu percobaan serta pengamatan yang berguna untuk penelitian selanjutnya (Hisbullah, 2018). Penelitian sebelumnya menyatakan bahwa hasil belajar oleh pendidik dilakukan secara berkaitan yang memiliki tujuan untuk meninjau dan meningkatkan efektivitas proses kegiatan belajar peserta didik. Penilaian hasil belajar dilaksanakan dalam bentuk penugasan yang dilakukan dengan menggunakan teknik serta bentuk instrumen yang tepat dengan kebutuhan (Latifah, 2019; Sri Wahyuningsih, 2020).

Temuan penelitian sebelumnya menyatakan bahwa metode Number Head Together (NHT) dalam pembelajaran merupakan metode alternatif untuk mengatasi masalah belajar (Yenni, 2016). Pembelajaran Numbered Head Together memberikan kesempatan kepada siswa untuk berbagi ide dan memikirkan jawaban yang benar secara bergiliran (Kristian, 2018). Metode NHT dapat meningkatkan hasil belajar siswa dibandingkan dengan pembelajaran konvensional (Cesari et al., 2016). Model NHT memberikan hasil yang efektif saat diterapkan pada proses pembelajaran (Pendy \& Mbagh, 2021). Penelitian sebelumnya dilaksanakan pada pembelajaran secara langsung. Sedangkan pada penelitian ini, pelaksanaan metode pembelajaran ini secara online dengan menggunakan aplikasi Zoom Meeting. Dengan penggunaan metode pembelajaran ini diharapkan mampu menaikkan hasil belajar IPA peserta didik pada materi kekayaan sumber energi di Indonesia dalam kehidupan sehari-hari. Penggunaan metode NHT diharapkan dapat meningkatkan partisipasi aktif siswa dalam kegiatan pembelajaran. Sehubungan dengan penjelasan tersebut, penelitian ini bertujuan untuk menganalisis pengaruh metode Numbered Head Together secara online terhadap hasil belajar IPA siswa kelas IV.

\section{METODE}

Jenis penelitian ini adalah penelitiat kuantitatif dan metode yang digunakan adalah quasi experimental dengan non-equivalent control group design. Subjek penelitian ini meliputi dua kelas yaitu kelas IVD kelas kontrol 31 siswa dan kelas eksperimen 31 siswa kelas IVD. Kelas kontrol menggunakan metode ceramah selama proses pembelajaran. Kelas eksperimen menggunakan metode pembelajaran NHT secara online. Populasi merupakan suatu target yang secara merata diperlukan untuk aktivitas riset (Nurdin, 2019). Populasi penelitian ini adalah seluruh siswa kelas IV SDN Cilangkap 01 Pagi Jakarta Timur tahun ajaran 2020/2021, sebanyak 6 kelas dengan jumlah siswa sebanyak 187 siswa dari kelas IV-A sampai dengan kelas IV-F. Populasi terjangkau dalam penelitian ini merupakan peserta didik kelas IV-D yang berjumlah 31 serta IV-E yang berjumlah 31 peserta didik di SDN Cilangkap 01 Pagi Jakarta Timur. Teknik yang digunakan untuk mendapatkan sampel penelitian adalah non-probability sampling. Jenis teknik pengambilan sampel yang digunakan adalah purposive sampling, yaitu suatu metode penentuan 
sampel berdasarkan tinjauan yang diberikan (Sugiyono, 2017). Sampel penelitian ini adalah seluruh populasi yang ada, yaitu siswa kelas IV-D dan IV-E SDN Cilangkap 01 Pagi Jakarta Timur.

Metode pengumpulan data ini dengan menerapkan tes pre-test dan post-test pada dua kelas sebagai hasil belajar yaitu kelas IV-D dan IV-E. Jenis instrumen yang digunakan adalah soal pilihan ganda. Soal yang diberikan berupa soal pilihan ganda dengan jumlah soal sebanyak 25 soal. Soal ini digunakan untuk menilai hasil belajar siswa di dua kelas tersebut. Uji validitas dalam penelitian ini menggunakan rumus Point Biserial dengan 30 soal pilihan ganda dan uji reliabilitas menggunakan rumus Kuder dan Richardson (KR 20). Metode pengumpulan data menggunakan pre-test dan post-test, sebanyak 25 alat penelitian pilihan ganda. Metode analisis data menggunakan uji normalitas Kolmogorov-Smirnov dan uji homogenitas Levene dan uji hipotesis menggunakan independent sample $t$-test. Teknik pengumpulan data yang dipakai adalah pengujian validitas serta reliabilitas. Pengujian validitas instrumen yang dipakai oleh peneliti dengan memakai rumus Point Biserial yang digunakan dengan bantuan program Microsoft Excel buat menghitung validitas soal. Instrumen yang dipakai berbentuk soal pilihan ganda dilengkapi kisi-kisi instrumen validitas disajikan pada Tabel 1.

Tabel 1. Kisi-Kisi Instrumen Validitas

\begin{tabular}{|c|c|c|c|c|c|c|}
\hline \multirow{2}{*}{ Kompetensi Dasar } & \multirow{2}{*}{$\begin{array}{c}\text { Indikator } \\
\text { Pembelajaran }\end{array}$} & \multicolumn{4}{|c|}{ Aspek Kognitif } & \multirow{2}{*}{$\begin{array}{l}\text { Jumla } \\
\text { h Soal }\end{array}$} \\
\hline & & C1 & C2 & C3 & C4 & \\
\hline $\begin{array}{l}\text { 3.5 Mengidentifikasikan } \\
\text { berbagai sumber energi, } \\
\text { perubahan bentuk energi, } \\
\text { dan sumber energi alternatif } \\
\text { (angin, air, matahari, panas } \\
\text { bumi, bahan bakar organik, } \\
\text { dan nuklir) dalam } \\
\text { kehidupan sehari-hari. }\end{array}$ & $\begin{array}{l}\text { 3.5.1 Menjelaskan } \\
\text { manfaat energi matahari } \\
\text { dalam kehidupan sehari- } \\
\text { hari. }\end{array}$ & $\begin{array}{c}1,3,6,9 \\
10,15,16,1 \\
7,18,21\end{array}$ & $\begin{array}{c}2,5,11,1 \\
2,13,14, \\
19,20,22 \\
, 23,24,2 \\
5,26,27 \\
29\end{array}$ & 7 & $\begin{array}{c}4, \\
8, \\
28 \\
, 3 \\
0\end{array}$ & 30 \\
\hline \multicolumn{2}{|c|}{ Jumlah } & 10 & 15 & 1 & 4 & 30 \\
\hline
\end{tabular}

Teknik analisis data yang digunakan adalah uji normalitas. Pengujian normalitas dilakukan untuk mengetahui apakah data pre-test dan post-test berdistribusi normal atau tidak (Purwasih \& Bernad, 2018). Uji normalitas pada penelitian ini menggunakan uji Kolmogorov-Smirnov dengan SPSS 28 for Windows. Uji homogenitas menggunakan uji Levene. Teknik untuk uji homogenitas ini memakai program SPSS 28 for Windows. Uji hipotesis menggunakan uji-t dengan signifikan $\alpha=5 \%$ atau 0,05 . Hasil uji statistik untuk menguji keakuratan hipotesis statistik yaitu menerima atau menolak $\mathrm{H}_{0}$, dan memahami pengaruh masing-masing variabel independen terhadap variabel dependen. (Novita et al., 2019; Rahayu \& Susanto, 2018), sedangkan pengujian $t$-tes Tingkat signifikansi adalah 0,05. Jika thitung $\leq t_{\text {tabel, }}$ maka dapat dikatakan bahwa metode Number Head Together (NHT) secara online tidak berpengaruh signifikan terhadap hasil belajar IPA materi kekayaan sumber energi di Indonesia siswa kelas IV. Jika thitung maka dapat dikatakan metode Numbered Head Together (NHT) signifikan. Uji Effect Size digunakan untuk menghitung besarnya pengaruh metode pembelajaran Numbered Head Together (NHT) terhadap hasil belajar IPA materi kekayaan sumber energi di Indonesia dengan klasifikasi disajikan pada Tabel 2.

Tabel 2. Interpretasi Effect Size

\begin{tabular}{cc}
\hline Rentang & Klasifikasi \\
\hline $\mathrm{d}<0,20$ & Kecil \\
$0,2<\mathrm{d}<0,50$ & Sedang \\
$05<1,00$ & Besar \\
$>1,00$ & Sangat Besar \\
\hline
\end{tabular}

\section{HASIL DAN PEMBAHASAN}

Pengujian validitas dilaksanakan untuk mengetahui soal yang telah dibuat valid atau drop. Pengujian validitas digunakan dengan menelaah butir soal menggunakan rumus korelasi Point Biserial. Dasar pengambilan keputusan dalam uji validitas adalah dengan mengukur nilai rhitung dengan rtabel, jika rhitung > rtabel bahwa soal tersebut dikatakan sah atau valid, dan jika rhitung $<$ rtabel maka soal tersebut dinyatakan tidak valid atau drop. Untuk mencari $\mathrm{r}$ tabel dapat digunakan rumus $\mathrm{df}=\mathrm{N}-2$, dalam penelitian ini diketahui $\mathrm{N}=31$ jika diaplikasikan dalam rumus maka $\mathrm{df}=31-2=29$ maka diperoleh hasil $\mathrm{r}$ tabel yaitu 
0,355. Berdasarkan hasil perhitungan 30 butir soal pilihan ganda melalui aplikasi Google Form yang sudah diuji coba kepada siswa kelas IVF di SDN Cilangkap 01 Pagi Jakarta Timur, maka hasil validitas dapat dikategorikan seperti pada Tabel 3.

Tabel 3. Hasil Uji Validitas Soal Pilihan Ganda

\begin{tabular}{ccc}
\hline Keterangan & Jumlah Soal & Nomor Soal \\
\hline \multirow{2}{*}{ Valid } & 27 & $1,2,3,5,6,7,9,10,11,12,13,14,15,16$, \\
Drop & 3 & $17,18,19,20,21,22,23,24,25,26,27,28,30$. \\
\end{tabular}

Dari data di atas maka diketahui bahwa soal pilihan ganda melalui Google Form dikatakan valid berjumlah 27 item, sedangkan soal yang tidak valid atau drop berjumlah 3 item. Maka instrumen yang digunakan untuk penelitian adalah 25 item soal. Uji reliabilitas ditentukan dengan membandingkan nilai

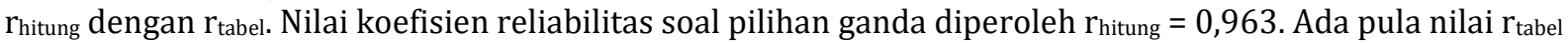
pada taraf signifikan $\alpha=0,05$ dengan $\mathrm{df}=29$ diperoleh $\mathrm{r}_{\text {tabel }}=0,355$. Berdasarkan nilai koefisien reliabilitas soal pilihan ganda dengan $r_{\text {tabel }}=0,355$ diketahui bahwa $r_{\text {hitung }}>r_{\text {tabel }}$ maka soal yang telah disusun dalam penelitian ini reliabel dengan klasifikasi sangat tinggi dan layak buat digunakan.

Penelitian ini dilakukan pada 2 kelas, yaitu di kelas kontrol maupun di kelas eksperimen sebanyak 2 kali dengan perlakuan yang berbeda, yaitu kelas kontrol menggunakan metode ceramah dan kelas eksperimen menggunakan metode NHT. Setelah diberikan perlakuan, kedua kelas itu diberikan akan post-test untuk memperoleh data dan mengukur kemampuan akhir siswa. Hasilnya adalah sebagai berikut. Nilai mean post-test hasil belajar IPA kelas kontrol yang tidak diberi metode NHT sebesar 76,13, dengan nilai varians yang berjumlah 55,983 dan standar deviasi sebesar 7,48. Nilai mean post-test hasil belajar IPA kelas eksperimen yang diberi metode NHT sebesar 89,16, dengan nilai varians yang berumlah 39,673 dan standar deviasi sebesar 6,29. Hasil post-test di kelas kontrol dan kelas eksperimen menunjukkan bahwa nilai mean atau rata-rata hasil belajar IPA pada kelas eksperimen lebih tinggi 13,03 dibandingkan dengan kelas kontrol. Perolehan data kelas eksperimen dan kelas kontrol dapat dilihat pada Tabel 4.

Tabel 4. Data Deskriptif Statistik Kelas Kontrol dan Kelas Eksperimen

\begin{tabular}{lcc}
\hline \multicolumn{1}{c}{ Hasil Ananlisis } & Kelas Kontrol & Kelas Eksperimen \\
\hline Mean & 76,13 & 89,16 \\
Median & 76 & 88 \\
Modus & 80 & 88 \\
Minimum & 64 & 72 \\
Maximum & 92 & 100 \\
Standar Deviasi & 7,48 & 6,29 \\
Varians & 55,983 & 39,673 \\
\hline
\end{tabular}

Berkaitan dengan tabel tersebut, diketahui bahwa hasil belajar siswa kelas eksperimen yang diberi treatment metode NHT secara online mendapatkan nilai lebih tinggi 13,03 dibandingkan dengan nilai kelas kontrol yang tidak diberi treatment metode NHT secara online. Kolmogorov-Smirnov digunakan pada penelitian ini sebagai uji normalitas untuk mengetahui normal atau tidak data yang ada. Rumus yang dipakai uji normalitas yaitu Kolmogorov-Smirnov bantuan SPSS 28 for Windows. Apabila nilai sig > 0,05 data berdistribusi normal dan jika sig $<0,05$ bahwa datanya tidak normal. Hasil penghitunngan dapat dilihat pada Tabel 5 .

Tabel 5. Uji Normalitas

\begin{tabular}{clcc}
\hline No. & \multicolumn{1}{c}{ Kelompok } & sig & Keterangan \\
\hline 1. & Pre-Test Kelas Eksperimen & 0,186 & Normal \\
2. & Post-Test Kelas Eksperimen & 0,148 & Normal \\
3. & Pre-Test Kelas Kontrol & 0,200 & Normal \\
4. & Post-Test Kelas Kontrol & 0,077 & Normal \\
\hline
\end{tabular}

Berdasarkan tabel tersebut, kelompok data berdistribusi normal karena nilai pre-test dan posttest melebihi nilai sig > 0,05, maka dapat disimpulkan bahwa kelompok data tersebut normal. Setelah menjalankan uji normalitas, lalu dilakukan uji homogenitas. Uji homogenitas dilakukan untuk mengetahui 
keseragaman varians. Rumus yang digunakan uji homogenitas yaitu uji Levene dengan bantuan SPSS 28 for Windows dengan taraf sig > 0,05. Hasil pengujian disajikan pada Tabel 6 .

Tabel 6. Uji Homogenitas

\begin{tabular}{cccc}
\hline Kelas & F hitung & sig & Keterangan \\
\hline Pre-Test & 0,280 & 0,599 & Homogen \\
Post-Test & 1,339 & 0,252 & Homogen \\
\hline
\end{tabular}

Berdasarkan analisis data uji homogenitas variabel penelitian diketahui nilai $F_{\text {hitung }}$ pre-test 0,280

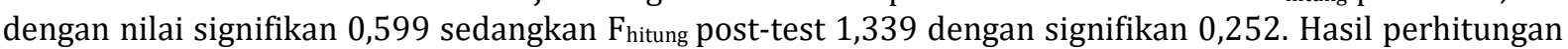
data pre-test dan post-test lebih besar dari sig $>0,05$. Maka dapat dinyatakan bahwa data pada penelitian ini homogen. Uji t dilakukan untuk mengetahui hasil belajar IPA kelas IV SDN Cilangkap 01 Pagi Jakarta Timur berpengaruh signifikan atau tidak terhadap metode pembelajaran online Numbered Head Together (NHT). Uji sampel independen dilakukan pada post-test kelas eksperimen dan kelas kontrol untuk mengetahui ada atau tidak ada pengaruh yang signifikan terhadap skor post-test kelas eksperimen dengan nilai post-test kelas kontrol. Kesimpulannya, hasilnya dikatakan signifikan apabila $t_{\text {hitung }}>t_{\text {tabel }}$ dengan signifikansi 5\% $(\alpha=0,05)$ dan $p$ value $<0,05$. Hasil uji independent sample t-test pre-test kelas eksperimen dan pre-test kelas kontrol ditunjukkan pada Tabel 7.

Tabel 7. Uji Independent Sample t-test

\begin{tabular}{lcccc}
\hline \multicolumn{1}{c}{ Kelas } & Rata-rata & thitung $_{\text {tas }}$ & t $_{\text {tabel }}$ & $\boldsymbol{p}$ \\
\hline Post-test Kelas Kontrol & 76,13 & & & \\
$\begin{array}{l}\text { Post-test Kelas } \\
\text { Eksperimen }\end{array}$ & 89,16 & 7,419 & 2,000 & $<0,001$ \\
\hline
\end{tabular}

Melalui uji hipotesis, diperoleh rata-rata nilai post-test kelas kontrol adalah 76,13 dan rata-rata nilai post-test kelas eksperimen adalah 89,16, sehingga rata-rata hasil belajar kelas eksperimen adalah 13,03 lebih tinggi daripada kelas kontrol. Dari tabel tersebut terlihat bahwa thitung sebesar 7,419 dengan signifikansi $<0,001$. Didapatkan tabel dari $\mathrm{df}=\mathrm{n}-\mathrm{k}=62-2=60$ pada taraf sigifikansi $5 \%(\alpha=0,05)$ adalah 2,000 . Jadi nilai thitung $>t_{\text {tabel }}$ pada taraf yaitu 7,419 > 2,000 dan mempunyai $p$ value $(<0,001<0,05)$. Artinya terdapat pengaruh yang positif dan signifikan antara metode pembelajaran Numbered Head Together (NHT) secara online terhadap hasil belajar IPA siswa kelas IV SDN Cilangkap 01 Pagi Jakarta Timur". Uji effect size digunakan untuk menguji pengaruh satu variabel pada variabel lain ialah variabel independen serta variabel dependen. Effect size digunakan sebagai ukuran berhasil ataupun tidaknya suatu penelitian. Rumus Cohen's $d$ dipakai untuk mengetahui pengaruh metode pembelajaran Numbered Head Together (NHT) secara online terhadap hasil belajar IPA siswa kelas IV. Hasil uji Effect Size ditunjukkan pada Tabel 8.

Tabel 8. Uji Effect Size

\begin{tabular}{ccccc}
\hline Kelas & $\overline{\mathbf{x}}$ (Rata-rata) & Standar Deviasi & Effect Size & Ket \\
\hline Kontrol & 76,13 & 7,482 & \multirow{2}{*}{1,88} & Sangat \\
Eksperimen & 89,16 & 6,299 & & Besar \\
\hline
\end{tabular}

Berdasarkan analisis data tersebut diperoleh nilai effect size sebesar 1,88 dengan predikat sangat besar dan metode pembelajaran Numbered Head Together (NHT) secara online memberi pengaruh yang sangat besar dan signifikan terhadap hasil belajar IPA siswa kelas IV SDN Cilangkap 01 Pagi Jakarta Timur. Hal itu dilandasi oleh beberapa faktor, di antaranya sebagai berikut. Pertama, pembelajaran dengan memakai metode Numbered Head Together secara online dapat meningkatkan hasil belajar IPA siswa. Metode pembelajaran Numbered Head Together merupakan metode yang mengutamakan keaktifan dan kerja sama siswa dengan tim dalam mengedepankan kegiatan berdiskusi/mencari untuk memecahkan suatu masalah serta siswa pun dapat mempresentasikan hasil diskusi bersama dengan kelompoknya (Maharani, 2016; Sugawara \& Nikaido, 2014). Kedua, metode pembelajaran Numbered Head Together secara online dapat meningkatkan semangat dan keaktifan siswa dalam proses belajar. Tujuan dari penerapan metode Numbered Head Together di antaranya agar siswa mampu belajar secara bekerja sama dengan saling menghargai argumen temannya dan memberikan kesempatan pada temannya yang lain untuk mengemukakan pendapat mereka secara berkelompok. Penggunaan metode NHT dalam 
pembelajaran mengakibatkan siswa menjadi lebih aktif dalam kegiatan belajar, meningkatkan kreativitas serta keterlibatan siswa dalam proses belajar mengajar (Pendy \& Mbagh, 2021).

NHT berbeda dengan cara pembelajaran kelompok biasa. Pada pembelajaran kelompok biasa yang mempresentasikan hasil kerja kelompok atau laporan kelompok bebas. Boleh disampaikan oleh salah seorang anggota kelompok. Tetapi pada NHT yang harus mempresentasikan hasil kerja kelompok atau laporan kelompok adalah nomor yang dipilih secara acak oleh guru, sehingga setiap siswa dalam kelompok merasa bertanggung jawab dalam diskusi kelompok. Beberapa kelebihan dari penggunaan metode pembelajaran NHT secara online di antaranya, peserta didik lebih mudah memahami dan menguasai materi, siswa mampu bekerja sama dengan baik dalam berdiskusi kelompok, dan hasil belajar siswa yang diberi metode Numbered Head Together secara online lebih tinggi dari siswa yang tidak diberikan metode tersebut. Kekurangan yang terjadi dalam penelitian ini di antaranya, keterbatasan waktu dalam penelitian yang mendekati dengan Penilaian Akhir Semester (PAS) serta kondisi pandemi COVID-19 yang tidak memungkinkan penggunaan metode pembelajaran Numbered Head Together dalam penelitian ini dilakukan secara tatap muka dan tidak semua siswa dapat mengikuti kegiatan pembelajaran dikarenakan keterbatasan teknologi.

Temuan penelitian ini diperkuat oleh temuan sebelumnya yang menyatakan bahwa hasil belajar Matematika siswa yang menggunakan metode NHTlebih baik daripada hasil belajar Matematika siswa yang menggunakan pembelajaran konvensional (Pendy \& Mbagh, 2021). Metode NHT dapat meningkatkan hasil belajar siswa dibandingkan dengan pembelajaran konvensional (Cesari et al., 2016). Model NHT memberikan hasil yang efektif saat diterapkan pada proses pembelajaran (Pendy \& Mbagh, 2021). Model pembelajaran NHT lebih tepat digunakan untuk mendukung siswa agar lebih meningkatkan kemampuan pemecahan masalah matematis siswa (Purnama et al., 2020). Implikasi pada penelitian ini bahwa pembelajaran dengan menggunakan metode Numbered Head Together secara online dapat digunakan pada saat pandemi seperti saat ini yang mengharuskan kegiatan pembelajaran secara online..

\section{SIMPULAN}

Metode pembelajaran Numbered Head Together secara online berpengaruh signifikan terhadap hasil belajar IPA siswa kelas IV. Guru diharapkan untuk berlatih metode Numbered Head Together secara online agar lebih kreatif dan dapat dikombinasi dengan metode pembelajaran yang lain untuk lebih meningkatkan pengaruh pembelajaran. Kegiatan pembelajaran menggunakan metode NHT secara online dapat terwujudnya pembelajaran aktif dan bermakna sehingga hasil belajar meningkat.

\section{DAFTAR PUSTAKA}

Andriyani, N. L., \& Suniasih, N. W. (2021). Development of Learning Videos Based on Problem-Solving Characteristics Of Animals and Their Habitats Contain in Science Subjects On 6th-Grade. Journal of Education, 5(1), 37-47. https://doi.org/10.23887/jet.v5i1.32314.

Arjuniwati. (2019). Motivasi dan Hasil Belajar melalui Penerapan Model Pembelajaran Numbered Heads Together (NHT) pada Materi Peluang Mata Pelajaran Matematika Kelas XII. Jurnal Pendidikan Tambusai, 3(1), 1-13. https://doi.org/10.31004/jptam.v3i1.197.

Cahyani, R., \& Suyadi, S. (2019). Konsep Pendidikan Anak Usia Dini Menurut Ki Hadjar Dewantara. Golden Age: Jurnal Ilmiah Tumbuh Kembang Anak Usia Dini, 3(4), 219-230. https://doi.org/10.14421/jga.2018.34-01.

Cesari, A. V., Imam, K., \& Wahyuni, S. (2016). Penerapan Numbered Head Together dengan Pendekatan Guided Note Taking pada Materi Hidrokarbon. Jurnal Inovasi Pendidikan Kimia, 6(2). https://journal.unnes.ac.id/nju/index.php/JIPK/article/view/6538.

Dewi, W. A. F. (2020). Dampak COVID-19 terhadap Implementasi Pembelajaran Daring di Sekolah Dasar. Edukatif: Jurnal Ilmu Pendidikan, 2(1), 55-61. https://doi.org/10.31004/edukatif.v2i1.89.

Hermanda, N. D., Hariyati, N., Pendidikan, M., Pendidikan, F. I., \& Surabaya, U. N. (n.d.). Pengaruh Supervisi Akademik terhadap Keefektifan Pembelajaran Daring pada Masa Pandemi. X, 739-748.

Hisbullah. (2018). Pembelajaran Ilmu Pengetahuan Alam di Sekolah Dasar (ke-1). Aksara Timur.

Kristian, A. (2018). Pengaruh Model Pembelajaran Numbered Head Together ( NHT ) terhadap Hasil Belajar Matematika Siswa di Kelas Iv Sdn 4 Banda Aceh. GENTA MULIA: Jurnal Ilmiah Pendidikan, IX(2), 71-82. https://ejournal.stkipbbm.ac.id/index.php/gm/article/view/169/157.

Latifah, N. (2019). Peningkatan Hasil Belajar IPA Materi Sumber Energim melalui Model Pembelajaran Kooperatif Tipe Kartu Arisan pada Siswa Kelas IV. Al - Azkiya : Jurnal Ilmiah Pendidikan MI/SD, 4(1), 87-94. https://doi.org/10.32505/azkiya.v4i1.1145.

Maharani, N. (2016). Peningkatan Hasil Belajar PKn melalui Model Pembelajaran Numbered Head 
Together (NHT) bagi Siswa kelas VI SDN 4 Ngraho Kedungtubun Blora Semester 1 tahun 2015/2016. Elementary School 3, 3(2), 195-215. https://doi.org/10.31316/esjurnal.v3i2.578.

Mansyur, A. R. (2020). Dampak COVID-19 terhadap Dinamika Pembelajaran di Indonesia. Education and Learning Journal, 1(2), 113. https://doi.org/10.33096/eljour.v1i2.55.

Muhammad Fikri, Muhammad Zaki Ananda, N. F. (2021). Kendala dalam Pembelajaran Jarak Jauh di Masa Pandemi Covid-19: Sebuah Kajian Kritis. Jurnal Education and Development Institut Pendidikan Tapanuli Selatan, 9(1), 145-148. https://doi.org/10.37081/ed.v9i1.2290.

Novita, L., Sukmanasa, E., \& Pratama, M. Y. (2019). Penggunaan Media Pembelajaran Video terhadap Hasil Belajar Siswa SD. Indonesian Journal of Primary Education Penggunaan, 3(2), 64-72. https://ejournal.upi.edu/index.php/IJPE/article/view/22103.

Nurdin, I. (2019). Metodelogi Penelitian Sosial (ke-1). Media Sahabat Cendekia.

Pendy, A., \& Mbagh, H. M. (2021). Model Pembelajaran Numbered Head Together (NHT) pada Materi Pokok Relasi dan Fungsi. Jurnal Basicedu, 5(4), 2156-2163. https://doi.org/10.31004/basicedu.v5i1.542.

Purnama, S., Pitaloka, A., \& Maharani, I. P. (2020). The Effectiveness of Somatic , Auditory , Visualization , and Intellectually and Numbered Head Together Learning Models Against Students Mathematical Problem Solving Capabilities. Jurnal Matematika, 3(2), 175-182. https: //doi.org/10.24042/djm.

Purwasih, R., \& Bernad, M. (2018). Pembelajaran Diskursus Multi Representasi terhadap Peningkatan Kemampuan Komunikasi dan Disposisi Matematis Mahasiswa. Jurnal Riset Pendidikan Matematika, 5(1), 43. https://doi.org/10.21831/jrpm.v5i1.13589.

Puspitorini, R., Prodjosantoso, A. K., Subali, B., \& Jumadi, J. (2014). Penggunaan Media Komik dalam Pembelajaran IPA untuk Meningkatkan Motivasi dan Hasil Belajar Kognitif dan Afektif. Jurnal Cakrawala Pendidikan, 3(3), 413-420. https://doi.org/10.21831/cp.v3i3.2385.

Putra, Seno Himala. (2019). Peningkatan Proses Pembelajaran Tematik dengan Menggunakan Pendekatan Problem Based Learning di Kelas III SD. Perspektif Pendidikan Dan Keguruan, VIII(1), 32-40. https: //doi.org/10.31227/osf.io/8qmrp.

Rahayu, R., \& Susanto, R. (2018). Pengaruh Kepemimpinan Guru dan Keterampilan Manajemen Kelas terhadap Perilaku Belajar Siswa Kelas IV. Jurnal Pendidikan Dasar Perkhasa: Jurnal Penelitian Pendidikan Dasar, 4(2), 220-229. https://doi.org/10.31932/jpdp.v4i2.178.

Rahma, N. A., \& Pujiastuti, H. (2021). Efektivitas Pembelajaran Daring Matematika pada Masa Pandemi Covid-19 Di Kota Cilegon [ The Effectiveness of Mathematics Online Learning During the Covid-19 Pandemic in Cilegon City ]. JOHME: Journal of Holistic Mathematics Education, 5(1), 1. https://doi.org/10.19166/johme.v5i1.3811.

Rigianti, H. A. (2020). Kendala Pembelajaran Daring Guru Sekolah Dasar di Kabupaten Banjarnegara. Jurnal Elementary School, 7(2), 297-302. https://doi.org/10.31316/esjurnal.v7i2.768.

Sri Wahyuningsih, E. (2020). Model Pembelajaran Mastery Learning Upaya Peningkatan Keaktifan dan Hasil Belajar Siswa (ke-1). DEEPUBLISH.

Sugawara, E., \& Nikaido, H. (2014). Properties of AdeABC and AdeIJK Efflux Systems of Acinetobacter Baumannii Compared with Those of the AcrAB-TolC System of Escherichia coli. Antimicrobial Agents and Chemotherapy, 58(12), 7250-7257. https://doi.org/10.1128/AAC.03728-14.

Sugiyono. (2017). Metode Penelitian Kuantitatif, Kualitataif, dan R\&D. Bandung: Alfabeta.

Susilawati, S., \& Supriyatno, T. (2020). Online Learning Through WhatsApp Group in Improving Learning Motivation in the Era and Post Pandemic COVID -19. Jurnal Pendidikan: Teori, Penelitian, Dan Pengembangan, 5(6), 852-859. http://journal.um.ac.id/index.php/jptpp/article/vi...

Susilo, Y., \& Khabibah, S. (2010). Peningkatan Motivasi Belajar Siswa melalui Model Pembelajaran Kooperatif Tipe Numbered Head Together ( NHT) Materi Ajar Perbandingan dan Fungsi Trigonometri pada Siswa Kelas X. MATHEdunesa, 2, 1.

SY, N., Corebima, A., \& Susilo, H. (2016). Pengaruh Strategi Pembelajaran Numbered Heads Together (NHT) terhadap Hasil Belajar Siswa SMA Negeri 1 Muara Badak. Jurnal Pendidikan: Teori, Penelitian, Dan Pengembangan, 1(10), 1993-1998-1998. https: //doi.org/10.17977/jp.v1i10.7310.

Yenni, R. F. (2016). Penggunaan Metode Numbered Head Together (NHT) dalam Pembelajaran Matematika. Jurnal Penelitian Dan Pembelajaran Matematika, 9(2), 263-267. https: //doi.org/10.30870/jppm.v9i2.1006.

Yulianingsih, W., Suhanadji, S., Nugroho, R., \& Mustakim, M. (2020). Keterlibatan Orangtua dalam Pendampingan Belajar Anak selama Masa Pandemi Covid-19. Jurnal Obsesi : Jurnal Pendidikan Anak Usia Dini, 5(2), 1138-1150. https://doi.org/10.31004/obsesi.v5i2.740. 